\title{
CYBERBULLYING, DIREITO EDUCACIONAL E RESPONSABILIDADE CIVIL: UMA ANÁLISE JURÍDICA E DEONTOLÓGICA DA REALIDADE BRASILEIRA
}

\author{
CYBERBULLYING, DERECHO EDUCATIVO Y RESPONSABILIDAD CIVIL: UN \\ ANÁLISIS JURÍDICO Y DEONTOLÓGICO DE LA REALIDAD BRASILEÑA
}

CYBERBULLYING, EDUCATIONAL RIGHT AND CIVIL RESPONSIBILITY: A LEGAL AND DEONTOLOGICAL ANALYSIS OF THE BRAZILIAN REALITY

Elcio Nacur REZENDE ${ }^{1}$

Lélio Braga CALHAU ${ }^{2}$

RESUMO: O presente artigo tem por objetivo investigar o Cyberbullying e a responsabilidade civil das escolas no Brasil. Buscou-se analisar aspectos da vida digital dos estudantes, relações sociais aceleradas na "sociedade de desempenho", a competitividade entre as escolas particulares, e como isso propicia um ambiente negativo que facilita o surgimento do Cyberbullying. Concluiu-se que, com o advento das primeiras três leis federais que tratam do bullying e cyberbullying no Brasil (2015-2018), a omissão dolosa das escolas em cumprir as normas descritas nessas leis acarreta prejuízos efetivos para toda a comunidade escolar, que fica desprotegida por não contar com um programa efetivo e permanente de prevenção e controle de atos de Cyberbullying. Utilizou-se de pesquisa bibliográfica e apontamentos doutrinários para a realização deste trabalho.

PALAVRAS-CHAVE: Cyberbullying. Bullying. Direito. Responsabilidade civil. Escolas. Educação.

RESUMEN: Este artículo tiene como objetivo investigar el ciberacoso y la responsabilidad civil de las escuelas en Brasil. Buscamos analizar aspectos de la vida digital de los estudiantes, relaciones sociales aceleradas en la "sociedad del rendimiento", competitividad entre escuelas privadas y cómo esto proporciona un entorno negativo que facilita el surgimiento del ciberacoso. Se concluyó que, con la llegada de las tres primeras leyes federales que se ocupan del acoso y el ciberacoso en Brasil (2015-2018), la omisión intencional de las escuelas para cumplir con las normas descritas en estas leyes implica pérdidas efectivas para toda la comunidad escolar, que está desprotegida porque no tiene un programa eficaz y permanente para la prevención y el control de los actos de ciberacoso. Utilizamos investigaciones bibliográficas y notas doctrinales para realizar este trabajo.

1. Escola Superior Dom Helder Câmara (ESDHC), Belo Horizonte - MG - Brasil. Professor dos Programas de Pós-graduação em Direito das Faculdades Milton Campos e da Escola Superior Dom Hélder Câmara. Procurador da Fazenda Nacional. Pós-doutor em Direito. ORCID: https://orcid.org/0000-0002-2369-8945. E-mail: direitopenal@gmail.com

${ }^{2}$ Faculdade Milton Campos (FMC), Belo Horizonte - MG - Brasil. Mestrando em Direito nas Relações Econômicas e Sociais. Promotor de Justiça do Ministério Público do Estado de Minas Gerais. Professor de Criminologia da Fundação Escola Superior do Ministério Público de Minas Gerais. Membro da American Society of Criminology. ORCID: https://orcid.org/0000-0003-1553-8834. E-mail: direitopenal@gmail.com 
PALABRAS CLAVE: Cyberbullying. Bullying. Derecho. Responsabilidad civil. Escuelas. Educación.

ABSTRACT: This article aims to investigate Cyberbullying and the civil responsibility of schools in Brazil. It sought to analyze aspects of students' digital life, accelerated social relations in the "performance society", the competitiveness between private schools, and how it provides a negative environment that facilitates the emergence of Cyberbullying. It was concluded that, with the advent of the first three federal laws dealing with bullying and cyberbullying in Brazil (2015-2018), the malicious omission of schools to comply with the norms described in these laws entails an effective harm to the whole school community. unprotected for not having an effective and permanent program of prevention and control of acts of Cyberbullying. We used bibliographical research and doctrinal notes to carry out this work.

KEYWORDS: Cyberbullying, Bullying, Law, Civil Liability, Schools, Education.

\section{Introdução}

A Internet veio para mudar de forma definitiva a civilização. Mas, tal qual o avião, ela pode ser usada para o bem ou para o mal. Infelizmente, o que se vê no dia a dia é que houve uma democratização e uma facilidade cada vez maior de acesso à rede mundial de computadores, mas a prática de atos ilícitos cíveis, muitas vezes incentivados por uma falsa sensação de anonimato, também se tornaram comuns e motivo de preocupação em vários países.

Nesse contexto, diversas condenações judiciais em ações de responsabilidade civil foram confirmadas em segunda instância nos últimos anos no Brasil, chamando a atenção das pessoas para o problema, que não diminui, pelo contrário, tem sido cada vez mais presente no mundo acadêmico.

As escolas estão envolvidas diretamente com o problema, haja vista que o Cyberbullying tem ocorrido com uma frequência indesejável e até mortes já ocorreram dentro de escolas públicas brasileiras por conta de conflitos envolvendo alunos em situação de Cyberbullying.

O presente artigo busca apresentar a questão da responsabilização civil das escolas por atos de Cyberbullying, e como a reprovabilidade desses casos, em nosso entendimento, aumentou muito com o advento das primeiras leis federais brasileiras, que regulamentam o combate ao bullying no Brasil.

Existe uma série de dificuldades para se conceituar o que é bullying e Cyberbullying. Há autores que defendem que o termo se refere apenas a fatos praticados entre pares, um 
sentido restrito, e há autores, muitos em países de língua inglesa, que utilizam a palavra bullying para situações que envolvam grupos sociais diversos exteriores ou não ao ambiente escolar

Neste artigo, iremos utilizar o conceito restrito de agressões virtuais entre pares, tendo em vista que o nosso objeto de estudo se limitará no presente caso à responsabilidade civil das escolas brasileiras, particulares ou públicas.

O problema que se enfrentará consiste na dificuldade efetiva que as escolas no Brasil têm se deparado para prevenir e reprimir situações de Cyberbullying em sua comunidade acadêmica.

O tema central que se abordará é como esse problema e o seu tratamento, que tem sido insuficiente pelas leis brasileiras, tem acarretado prejuízos para a comunidade acadêmica e pode sujeitar as escolas, bem como diretores e coordenadores, a pesados processos judiciais.

O objetivo que se espera atingir é a demonstração de que o cumprimento das normas federais, que tratam do bullying e cyberbullying, e, em especial, as leis federais 13.185/15, 13.277/16 e 13.6663/18, devem ser cumpridas integralmente para garantir um ambiente acadêmico seguro para toda a comunidade escolar.

Justifica-se este estudo na medida em que o Brasil aparece, em várias pesquisas internacionais, como um dos países com maior incidência de atos de Cyberbullying no mundo, e as medidas que vem sendo adotadas na atualidade não apontam uma redução concreta e sistêmica de atos de Cyberbullying no meio escolar.

Utilizou-se o método técnico-jurídico com técnica de pesquisas bibliográfica e jurisprudencial.

O referencial teórico escolhido para a presente pesquisa foi estruturado em seis tópicos: Vida digital; Direito educacional e Cyberbullying: O advento das primeiras leis federais que regulamentam o bullying e cyberbullying no Brasil; Da não implantação efetiva dos programas de prevenção e combate ao bullying criados pela lei federal 13.185/15 (artigo $\left.4^{\circ}\right)$.

Em caso de maior reprovabilidade, defendemos, por consequência, que os valores a serem pagos devam ser estipulados em patamares superiores aos fixados pelo Poder Judiciário para os chamados "casos antigos", ou seja, os que foram praticados antes de 2015, quando houve o advento da Lei Federal 13.185/15, primeira lei federal que tratou do tema no Brasil. 


\section{Vida digital, estudantes e cyberbullying}

Ninguém duvida que a vida digital moderna mudou profundamente a sociedade e as formas como nos relacionamos. Muitas novidades positivas surgiram com os processos de digitalização social, entre eles, o acesso ao conhecimento, que se tornou muito mais fácil e democrático.

Hoje, podemos, em muitas situações gratuitamente, assistir palestras, cursos etc, que estão sendo transmitidos online ou foram arquivados e disponibilizados no Youtube, Vimeo ou através de mecanismo próprios de escolas, que podem estar do outro lado do planeta, e que nunca teríamos acesso ou de forma extremamente cara para a grande maioria da população.

A vida digital também trouxe dificuldades, não apenas pelos descobrimentos tecnológicos, mas pelo mau uso que algumas pessoas fizeram com o acesso a essas novas tecnologias e, entre os problemas, não podemos deixar de registrar inicialmente a falsa sensação de anonimato e a efemeridade dos relacionamentos líquidos, nomenclatura criada por Bauman.

Nesse contexto, as escolas foram atingidas fortemente por essas mudanças, que, num primeiro momento, poderiam ser exemplificadas como dúvidas sobre se o telefone celular (um verdadeiro microcomputador na atualidade) deveria ser proibido ou não dentro de sala.

As transformações foram muito além disso.

Hoje, por força da velocidade da vida digital, enfrentamos conceitos novos e desafiadores dentro da comunidade escolar, como a própria existência virtual da "Sala 24 Horas", onde alunos expandem o círculo de relacionamento estudantil, através de grupos de Whatsapp, por exemplo, e interagem sobre assuntos da sua realidade escolar, mesmo fora do horário de funcionamento de sua escola.

E as próprias interações entre os estudantes sofreram profundas mudanças, no que Wendt e Weber (2014, p. 41) advertem:

[...] Antes da aparição dos modernos telefones celulares (smartphones), quando o acesso à internet era mais restrito e a popularidade das redes sociais não era tão evidente, as crianças e adolescentes interagiam, sobretudo, através de amizades próximas e face a face com vizinhos, parentes e colegas de escola. Não que este tipo de interação tenha desaparecido, mas uma mudança qualitativa pode ser observada na atualidade. As conexões que o mundo virtual possibilita potencializam o número de interações e tornam evidenciadas as interações virtuais. Não é raro, hoje em dia, ouvir declarações de tipo "eu possuo mais de 80 amigos em uma determinada rede social" ou, ainda, "eu participo, simultaneamente, de dezenas de fóruns online". 
E a competitividade cada vez mais acirrada do meio escolar, que pode resultar no fechamento ou não de um estabelecimento, por conta da não entrega de resultados com a aprovação de seus alunos em seleções para bons cursos e universidades públicas, foi acirrada cada vez mais com a velocidade de novos comportamentos sociais dos estudantes.

Sobre a importância da velocidade e a aceleração na vida social digital moderna, Trivinho (2017, p. 21) afirma:

[...] Como se sabe, a aceleração finca cadinho avassalador, tão intraconexo quanto aberto à infinitude, de metamorfoses referenciais, num caleidoscópio que renuncia a deixar impune qualquer vivente, na teia que abrange desde a esfera do trabalho à do tempo diário liberado, e vice-versa. Considerada uma realidade qualquer, dada em algum âmbito, setor ou segmento de atuação humana, ao ser submetida a onda contínua de aceleração, nada, deles, permanece como antes. A velocidade, qual fibroso fio silente c condutor, mata e vivifica, pulveriza e reconstrói, relativiza e consolida, supera e lança adiante, e se mantém estável em ciclos infindos dessa mesma operação, refazendo o mundo segundo o seu espelho.

O aluno e seus responsáveis legais, o professor, o coordenador pedagógico, o diretor, todos os funcionários administrativos da escola, também são influenciados por essa aceleração e até devem se superar para acompanhá-las, visto que, não em poucos casos, os alunos dominam muito mais essas novas tecnologias do que os adultos com quem interagem.

Essa aceleração social, que impacta também (e adoece e muito) o meio escolar, traz resultados positivos, mas cobra um preço alto das pessoas. E com a questão dos valores, que em muitos casos, não são trabalhados de uma forma efetiva na escola, os alunos acabam confundido atos negativos como o Cyberbullying com "zoações" ou "meras brincadeiras".

Cyberbullying são atos que fazem parte das microviolências nas escolas e não podem ser tolerados, sob nenhum pretexto, não só pela diretoria, coordenação pedagógica, bem como por todos os outros personagens da comunidade acadêmica.

E a gravidade dos atos de Cyberbullying é bem superior, como regra geral, do que os atos praticados no bullying tradicional, haja vista que por conta dos compartilhamentos as ofensas ou ameaças podem ser distribuídas, em pouco tempo, para milhares de internautas, atravessando estados, países, em ultra velocidade em caso de viralização dos compartilhamentos, com objetivo claro de causar um grande sofrimento emocional na vítima, enquanto no bullying tradicional, em regra, se limitam a uma sala, colégio, etc.

Sobre a maior gravidade concreta do Cyberbullying, lembra Rocha (2012, p. 82):

A mobilidade das tecnologias digitais tira o sossego das vítimas, o que faz do Cyberbullying uma forma de violência invasiva que ameaça os indivíduos 
em diferentes locais. Portanto, e como não acontecia no bullying tradicional, o lar já não [é um lugar de refúgio para a vítima, que continua recebendo pelo SMS ou pelos e-mails em qualquer lugar que vá.

Estes processos sociais de aceleração social e competitividade encontram um terreno fértil para a ocorrência de atos de bullying e Cyberbullying nas escolas, que não trabalham, em especial, com a efetiva valorização da convivência escolar.

Conviver bem não é apenas realizar palestras e afixar cartazes pela escola dizendo que esta escola valoriza a convivência escolar. É muito mais do que isso e deve ser procurado diuturnamente com um trabalho sério, coerente e permanente de valorização da convivência escolar e a cultura de paz.

Sobre esse problema dos valores morais e a convivência nas escolas, advertem Tognetta, Vinha e Bozza (2014, p. 205):

É como se houvesse uma relação simbiótica de causa e efeito dos valores de hoje e os relacionamentos violentos: é certo que existe um aumento gradativo das formas de relacionamento violento entre jovens e adultos; assim, a violência parece ser um valor entre as pessoas. Ao mesmo tempos, é também evidente que os valores aos quais a sociedade moderna atribui peso maior são pouco ou nada morais: a fama rápida, a virilidade, a força física, a juventude, o fato de "se dar bem na vida" custe o que custar, entre outros. Tais valores parecem superestimar uma cultura egoística do eu sobreposto ao outro. Com eles, a violência não é sentida como um desrespeito, e valores como a humildade, a generosidade e a justiça são pouco incorporadas.

Com o rompimento de paradigmas digitais e não se trabalhando a convivência escolar nas escolas, surge um ambiente negativo, extremamente competitivo, eventualmente individualista (e egoístico) e com maior propensão para a ocorrência de atos de Cyberbullying entre os alunos.

\section{A sociedade do desempenho e a autocoerção no ambiente escolar}

Quem não se adequa a essas mudanças facilmente fica desatualizado, podendo ter dificuldades presentes ou futuras de ingressar ou até mesmo se manter no mercado de trabalho.

O aluno que não se esforça, que tenha alguma dificuldade de aprendizagem, ou que por outro motivo não entrega bons resultados, acaba sendo excluído do círculo acadêmico e passa uma situação de fragilidade, podendo até adoecer por não alcançar os pesados resultados e expectativas da comunidade escolar. 
Nesse contexto, o mercado está cada vez mais competitivo e o desempenho individual do aluno pode ser a diferença entre ingressar ou não em um curso, faculdade ou universidade, que lhe projetará socialmente e poderá determinar o derradeiro sucesso ou fracasso de seu futuro profissional. Há a pressão por resultados, mas, por outro lado, também há um abismo, tendo em vista que a escola tem dificuldade de conseguir a atenção dos alunos

Mosé (2015) alerta sobre isso, que acaba sendo um paradoxo, pois há uma infantilização dos alunos, mas, ao mesmo tempo, eles são cobrados para entregarem resultados, e, em muitas situações nas escolas particulares, quando não apresentam bons resultados são "convidados" ou incentivados a se transferirem, para não atrapalhar as notas finais da própria escola e dos colegas:

As escolas, em geral, não se preocupam com o que o aluno aprendeu, mas com o que foi "ensinado" pelos professores, pouco ou nada sabem do aluno, muitas vezes o reconhecem com um número na chamada, não o acompanham em sua singularidade e usam a reprovação como um modelo de responsabilizá-lo, isentando-se do fracasso, que na verdade envolve os implicados no processo. A infantilização dos alunos, mesmo no Ensino Médio, resulta da passividade em que são colocados, como meros reprodutores de conteúdos com os quais na maioria das vezes não têm nenhum tipo de relação (p. 67).

A pressão para que a escola entregue resultados é imensa. As propagandas das escolas particulares, quase sempre, enaltecem os resultados positivos de seus alunos e isso reflete financeiramente em mais inscrições e a atração de novos alunos com potencial de levar a escola a melhores resultados no curto prazo.

Sobre a realidade dessa "sociedade de desempenho" e o modelo de superação irracional e individual, que pressiona o indivíduo a buscar produzir cada vez mais e entregar resultados mesmo acima de suas condições físicas e psicológicas, Han (2017, p. 70-71) adverte:

Como contraponto, a sociedade do desempenho e a sociedade ativa geram um cansaço e esgotamento excessivos. Esses estados psíquicos são característicos de um mundo que se tornou pobre em negatividade e que é dominado por um excesso de positividade. Não são reações imunológicas que pressuporiam uma negatividade do outro imunológico. Ao contrário, são casadas por um excesso de positividade. O excesso da elevação do desempenho leva a um infarto da alma. 
Por outro lado, surgiram novos problemas concretos como a forma de relacionamento entre os membros da comunidade acadêmica no meio digital. A aceleração inibe a reflexão e problemas se multiplicam na relação acadêmica da comunidade na seara digital ${ }^{3}$.

Ou o aluno se adequa a esses novos tempos ou o seu futuro pode ser tenebroso por conta de não se superar nessa incansável luta para superar o seu desempenho, quebrar metas e atingir melhores resultados, enaltecendo, também, toda sua comunidade escolar,

E tanto o bullying, como, em especial, o Cyberbullying, são elementos presentes cada vez mais na vida dos jovens e podem desequilibrar emocionalmente os alunos e atrapalhar (e muito) o desempenho, e até colocar em risco o seu futuro profissional.

Trata-se de uma realidade que traz intranquilidade para as escolas, e que não pode ser colocada de lado pela direção ou ter a sua gravidade subestimada, a fim de evitar algum pequeno desgaste momentâneo com o nome da escola por ser envolvida em possível situação de Cyberbullying.

É um fato a ser enfrentado permanentemente e não apenas após a sua ocorrência. Combater o Cyberbullying é processo, demanda programa sério, efetivo e não apenas atos isolados e desorganizados.

Sobre o enfrentamento de situações de bullying no Brasil pelas escolas, ensina Costa (2011, p. 132-133):

O bullying parece ser inerente ao processo social nas escolas, estudos reportam sua ocorrência em vários níveis escolares. Suas causas são diversas e têm como perspectiva de fundo as relações de poder entre as pessoas, as diferenças individuais e étnicas e a formação moral e de caráter do jovem e de sua família. As consequências são ruins para a escola, para a sociedade, assim como para as vítimas e para aqueles que praticam o bullying. $\mathrm{Na}$ atualidade, com a aplicação do acesso à Web e a emergência das redes sociais virtuais, o Cyberbullying surge como mais uma forma de expressão dos ataques e dos constrangimentos às pessoas. $\mathrm{O}$ Brasil carece de políticas públicas que permitam enfrentamento mais objetivo do problema. A sociedade e a escola estão tomando consciência do processo de violência que se desenvolve no interior das salas de aula, e já surgem pesquisas discutindo e aprofundando o assunto, possibilitando políticas e ações preventivas. Mais do que tudo, a melhor política sempre será a busca por uma educação de qualidade, que privilegie a formação cidadã em consonância com os princípios éticos e morais da sociedade.

Nesse contexto, é missão do Direito e da Educação, juntamente com a Psicologia, o Serviço Social, a Ciência da Computação, etc, se unirem, interagirem, atuarem de forma

\footnotetext{
${ }^{3}$ Podemos citar os conhecidos conflitos escolares, que surgem, por ações irrefletidas de usuários, nos conhecidos grupos de Whatsapp de pais de alunos de uma determinada escola. Comentários inadequados ou abusivos, volta e meia saem daquele ambiente diretamente para a delegacia de polícia.
} 
transdisciplinar, trazendo cada um dos saberes, o seu olhar, a sua percepção e a sua contribuição para que a escola seja resgatada, a convivência escolar seja valorizada (e não apenas os resultados) e a cultura de paz seja efetiva, gerando um ambiente positivo, para que todos, sem exceção, possam exercer as suas potencialidades e, com a ajuda da escola, atingir seus objetivos.

\section{Direito educacional e cyberbullying}

Recente pesquisa da consultoria internacional IPSOS (2018) apontou que o Brasil possui um dos maiores índices de ocorrências de Cyberbullying no mundo. O país ficou em segundo lugar, perdendo apenas para a Índia, na quantidade de casos de Cyberbullying.

Tanto o Bullying como o Cyberbullying apresentam grandes desafios para a comunidade escolar, bem como para a própria sociedade civil. Junto com a indisciplina, as incivilidades, assédios de vários tipos (moral, sexual etc), eles fazem parte da violência que atrapalha e traz nocivos resultados para todos os membros da comunidade escolar.

Sobre a violência nas escolas, Cabral e Lucas (2010, p. 70) advertem:

Entre avanços e retrocessos, a escola vai sendo conduzida em meio à nossa perplexidade, na busca de entendimentos que possibilitem sua coexistência junto aos novos paradigmas que se apresentam sob a forma de desafios, configurados na prática docente cotidiana, que ilumina os hiatos reais entre o que se quer e o que se pode, entre o que se deve fazer, mas não é viável.

O Direito Educacional enfrenta esse poderoso obstáculo e o Cyberbullying é um fator significante de desestruturação da paz na comunidade escolar. Qualquer estudante tem, em grau maior ou menor, medo de ser vítima de ataques violentos pelas redes sociais e ter a sua reputação social machada perante o seu grupo social.

O Direito Educacional não pode se furtar disso também. Ele trata das normas e princípios que afetam a realidade escolar, estando distribuídas entre normas constitucionais, leis, decretos, portarias e uma série de atos administrativos, que regulam, com menor ou maior amplitude, o trabalho de todos que lidam no meio escolar e os seus respectivos alunos.

A Constituição Federal de 1988 traz várias normas que asseguram a educação como um direito social ${ }^{4}$, tendo o seu artigo 205 determinado que a educação, direito de todos e dever do Estado e da família, será promovida e incentivada com a colaboração da sociedade,

\footnotetext{
${ }^{4}$ Art. $6^{\circ}$ São direitos sociais a educação, a saúde, a alimentação, o trabalho, a moradia, o transporte, o lazer, a segurança, a previdência social, a proteção à maternidade e à infância, a assistência aos desamparados, na forma desta Constituição. (Redação dada pela Emenda Constitucional nº 90, de 2015)
} 
visando ao pleno desenvolvimento da pessoa, seu preparo para o exercício da cidadania e sua qualificação para o trabalho.

A interpretação das normas de Direito Educacional, distribuídas tanto na esfera federal, estadual ou municipal, não podem se esquivar de atingir os preceitos constitucionais que tratam do assunto.

Além disso, o Direito Educacional deve ser interpretado em equilíbrio com outros instrumentos jurídicos, que afetam o funcionamento das escolas no seu dia a dia, entre eles o Código Civil, Código de Defesa do Consumidor, Estatuto da Criança e do Adolescente, entre outras.

Um dos grandes problemas enfrentados pelas escolas é a falsa percepção de anonimato, que muitos estudantes possuem ao navegar pela Internet. O anonimato é vedado pela Constituição Federal e essa falsa sensação gera, em algumas pessoas, uma errônea percepção de viver numa "terra de ninguém" quando se está navegando na internet.

Sobre a questão do anonimato na vida digital, Han (2018, p. 14) adverte:

$\mathrm{O}$ respeito está ligado a nomes. Anonimidade e respeito se excluem mutuamente. A comunicação anônima que é fornecida pela mídia digital desconstrói enormemente o respeito. Ela é corresponsável pela cultura de indiscrição e de falta de respeito [que está] em disseminação. Também o Shitstorm é anônimo. É nisso que consiste a sua violência. Nome e respeito estão ligados um ao outro. O nome é a base para o reconhecimento, que sempre ocorre de modo nominal [namentlich]. Também estão ligados à nominalidade [namentlichkeit] práticas como a responsabilidade, a confiança ou a promessa. Pode-se definir a confiança como a crença nos nomes. A responsabilidade e a promessa também são um ato nominal. A mídia digital, que separa a mensagem do mensageiro, o recado do remetente, aniquila o nome.

E talvez, como um dos outros grandes problemas, estão os atos irrefletidos, que nem todos adultos conseguem controlar, mas que os jovens, mais ainda, acabam praticando no meio digital e se envolvem em situações de Cyberbullying.

O Cyberbullying é, nesse contexto, ato ilícito civil de grande gravidade para os envolvidos e capaz de causar graves prejuízos para as suas vítimas. Ele tem causado grande intranquilidade social dentro e fora das escolas. E não poder ser admitido, por ser um ato que fere gravemente a dignidade das pessoas humanas. 
Com o advento da Lei Federal 13.185/15 $5^{5}$, o legislador brasileiro optou por utilizar a expressão "intimidação sistemática" para o bullying no Brasil, denominação não utilizada pela doutrina nacional, que prefere seguir se referindo ao tema apenas como bullying. ${ }^{6}$ Sobre o Cyberbullying (artigo $2^{\circ}$, parágrafo único da mesma lei), há intimidação sistemática na rede mundial de computadores (Cyberbullying), quando se usam os instrumentos que lhe são próprios para depreciar, incitar a violência, adulterar fotos e dados pessoais com o intuito de criar meios de constrangimento psicossocial.

Essa lei tratou do Cyberbullying apenas em seu conceito, mas é inegável que todas as normas dessa mesma lei para as escolas valem também para as situações de Cyberbullying, pois não haveria sentido da referida lei incluir o conceito de Cyberbullying em seu bojo se o legislador não quisesse que as normas do bullying valessem também para o Cyberbullying.

Um leitor desavisado pode ser tentado a achar que esta lei somente trata do bullying tradicional, mas uma interpretação sistemática desse ponto em conjunto com a Constituição Federal, o Estatuto da Criança e do Adolescente e o próprio Código de Defesa do Consumidor aponta que as normas da Lei 13.185/15 valem para o bullying tradicional e o Cyberbullying.

\section{Cyberbullying, selfies, narcisismo e o comportamento digital dos jovens}

O Cyberbullying é hoje um dos grandes desafios das escolas no mundo e, também, no Brasil. São inúmeros os casos de ataques pelas redes sociais e por mensagens de celular com ameaças, calúnias, difamações, injúrias, etc, que causam muita dor para as vítimas e ansiedade e percepção de caos no ambiente escolar, o que atrapalha o rendimento dos alunos e serve como desintegrador da qualidade do ambiente.

Nos Estados Unidos da América, grande parte dos estados já possuem leis que tratam do assunto, mas ainda inexiste uma lei federal sobre o problema. Cada país tenta, dentro de sua realidade e cultura, combater o problema. Não há mais espaço para omissão por parte das autoridades escolares, governos e pais.

Sobre a dificuldade que o tema é tratado nos EUA, dizem Bauman e Meter (2019, p. 41):

5 BRASIL. Lei Federal n. 13.185, de 6 de novembro de 2015. Institui o Programa de Combate à Intimidação Sistemática (Bullying). Diário Oficial da União, Brasília, 09 nov. 2015. Disponível em: http://www.planalto.gov.br/ccivil_03/_ato2015-2018/2015/lei/113185.htm. Acesso em: 13 abr. 2019.

${ }^{6}$ Por outro lado, o uso da expressão "intimidação sistemática" possui fatores positivos, como demonstrar que bullying são perseguições e não a ocorrência de atos isolados no meio escolar, que podem ser caracterizados como ato infracional análogo a um crime (ameaça, lesão corporal, difamação, calúnia, injúria etc). Um ato isolado não será bullying, mas poderá ser considerado um ato infracional ou até um ilícito civil, e submeter os pais do aluno, na forma do artigo 932, I, do Código Civil, também a uma situação de responsabilização civil. 
Não existem leis federais contra o cyberbullying, mas a existência da Primeira Emenda da Constituição torna as questões jurídicas um pouco confusas. Enquanto os estudantes têm direito à liberdade de expressão garantida pela Primeira Emenda, o Supremo Tribunal Federal manteve algumas restrições à liberdade de expressão no ambiente escolar para proteger os estudantes de danos causados por discursos disruptivos (Hofheimer, 2013). Ações judiciais desafiaram os tribunais a especificar que tipos de discurso fora do campus podem ser restringidos e sob quais condições. Isto é, algumas regras da escola podem estar em conflito com os direitos da Primeira Emenda dos estudantes. O precedente legal citado nestes casos é o do Distrito Escolar Comunitário Independente Tinker v. Des Moines (nd), no qual o tribunal concluiu que, quando o discurso causa uma "ruptura material e substancial" do ambiente de aprendizagem na escola, a escola tem a autoridade para impor consequências disciplinares ao criador do discurso. Outro padrão que tem sido aplicado em desafios legais é que deve haver um "nexo" entre o discurso e a escola quando o discurso é criado fora do campus ${ }^{7}$.

Lidar com o Cyberbullying demanda a adoção de novos padrões de comportamentos e iniciativas para resolver esse desafio. Não se trata de um problema próprio do Brasil, mas de todas as nações. Enquanto o bullying começou a ser discutido e estudado nos anos 70 na Escandinávia, no Brasil só passamos a lidar mais efetivamente com o problema em meados dos anos noventa.

A primeira lei federal brasileira surgiu apenas em 2015, quando, com mais de quarenta anos de atraso, encontramos um ambiente de grande intranquilidade nas escolas brasileiras, agravado, nos últimos anos, por notórios atos de violência e atentados nas escolas, com pessoas envolvidas em situações de bullying em seu passado.

A vida digital impõe a todos nós direitos e deveres, entre eles, o respeito à dignidade e à integridade emocional de terceiros. Um dos fatores que tem contribuído para a ocorrência do Cyberbullying nas escolas é a situação quando a própria vítima publica postagens que podem ser utilizadas contra ela mesmo no futuro.

Infelizmente, o individualismo, por parte de um grupo considerável de estudantes, grassa nas escolas. Competição, um certo desencanto com o futuro e a vontade de atingir

\footnotetext{
${ }^{7}$ Texto original: There are no federal laws against cyberbullying, but the existence of the First Amendment of the constitution makes legal issues somewhat muddy. While students have the right to free speech guaranteed by the First Amendment, the Supreme Court has upheld some restrictions on free speech in the school setting to protect students from harm caused by disruptive speech (Hofheimer, 2013). Lawsuits have challenged the courts to specify what types of off-campus speech can be restricted and under what conditions. That is, some school rules might be in conflict with the First Amendment rights of students. The legal precedent cited in these cases is that of Tinker v. Des Moines Independent Community School District (n.d.), in which the court concluded that, when speech causes a "material and substantial disruption" of the learning environment at school, the school has the authority to impose disciplinary consequences on the creator of the speech. Another standard that has been applied in legal challenges is that there must be a "nexus" between the speech and the school when the speech is created off-campus.
} 
rapidamente os objetivos sem questionar a forma, tem proporcionado um individualismo entre os alunos, que não só os afasta, como proporciona ideias profundamente egoístas e um certo desprezo com a figura do outro.

Quando abrimos as redes sociais dos estudantes, em muitos casos, encontramos um mundo irreal e um culto de si, que se aproxima de uma religião privada. Este tipo de cenário no ambiente escolar não só propicia a ocorrência de Cyberbullying como o agrava, pois se a própria comunidade vive com intensidade esse nível de individualismo, não há espaço para a empatia, a solidariedade, a pacificação social, o desprendimento e a busca de Justiça.

É terrivelmente uma situação de "cada um por si”, que só tende a deteriorar as relações sociais no ambiente escolar, já que o Eu será o rei de tudo na vida do indivíduo e problemas comunitários como o Cyberbullying não serão de interesse das pessoas, que não se envolverão por toda uma série de motivos para impedir ou cessar uma situação de bullying ou Cyberbullying.

Sobre esse culto de si, Roudinesco (2006, p. 52) adverte:

Enquanto formação psíquica que se traduz socialmente pelo culto do narcisismo, a obsessão por si mesmo é sempre portadora de uma rejeição do outro transformada em ódio de si e, portanto, em ódio pela presença do outro em si. Nessa perspectiva, esse culto seria a forma moderna tanto de uma consumação do declínio da família patriarcal quanto um desafio lançado á psicanálise. Esta havia efetivamente combatido a soberania do eu encarnada pelo pai da horda primitiva, antes de ser, por sua vez superada pelo Narciso. Se Édipo é a tragédia do assassinato do pai e do confronto com a verdade, Narciso é o drama de um eu que se subtrai progressivamente a qualquer encontro com a verdade ao substituir o peso das tradições pelo deleite de si e a punição da lei pelo cuidado terapêutico.

Muitas situações de Cyberbullying na escola poderiam ser detidas ou minimizadas se os primeiros alunos não compartilhassem ou reprovassem de forma efetiva as postagens negativas; mas, pelo contrário, mesmo não concordando, eles as compartilham e elas acabam viralizando e causando uma grande dor e prejuízo para a integridade moral e psicológica das vítimas e seus familiares.

Isso fica muito visível com a postura de publicação de selfies por parte dos estudantes, que é feita, em muitos casos, sem os cuidados preventivos de se modular o acesso da configuração de privacidade de seu perfil na rede social. O excesso de selfies ou postagens, em muitos casos, sem a devida reflexão e autocrítica, na velocidade acelerada do mundo dos jovens desse início do século XXI, só concorre para aumentar o problema.

Sobre os selfies e a postura de grande parte dos adolescentes nas redes sociais, leciona Aiken (2017, p. 165): 
As selfies trazem um novo significado ao mundo autoconsciente. Esses autorretratos rápidos e aparentemente inocentes - geralmente feitos com um smartphone ou webcam e compartilhada via mídia social - servem para muitas funções. Podem ser uma visão preconcebida de um eu público, um momento de satisfação, uma demonstração de humor ou uma declaração de ironia ao mundo, quase uma performance. $\mathrm{O}$ onipresente telefone celular com sua tecnologia de câmera de imagem espelhada torna os autorretratos fáceis de capturar, excluir, filtrar ou corrigir e ainda mais fáceis de compartilhar ${ }^{8}$.

O adolescente, no calor da juventude, não espera que fotos suas, bêbados em via pública ou até de cenas privadas possam, eventualmente, serem manipuladas ou até distribuídas para centenas de milhares de pessoas, após uma ligeira edição, trazendo um dano para a sua própria reputação.

Quando a escola simplesmente se omite de trazer essas informações para a sua própria comunidade acadêmica, os resultados podem ser ainda mais desastrosos.

Comentando o que sugere ser uma epidemia global de cyberagressões, Scheff (2017, p. 59) adverte que a própria vítima pode contribuir, também, para essas agressões virtuais:

Por que publicamos coisas que sabemos que poderiam nos causar problemas? Não estamos pensando nisso no calor do momento, ou achamos que ninguém está prestando atenção? Somos simplesmente ingênuos, pensando que o que dizemos é apenas entre amigos? Ou somos o oposto, ansiando pela aprovação de todos esses gostos ou retweets? Como veremos, muitas vezes essas bagunças são inteiramente feitas por nós mesmos. Seu comportamento on-line deve ser o melhor reflexo de quem você é off-line, mas muitos de nós não correspondem a esse ideal ${ }^{9}$.

Quando uma pessoa pratica o Cyberbullying ela viola direitos e fere a dignidade das vítimas.

Tais atos são mais graves que o bullying tradicional, pois as ofensas podem ser espalhadas pela internet e chegarem ao conhecimento de milhares de pessoas, aumentando o sofrimento das vítimas e a reprovabilidade dos atos praticados pelos autores.

Segundo Calhau (2019, p. 120-121):

\footnotetext{
${ }^{8}$ Texto original: Selfies bring new meaning to the world self-conscious. These quick, seemingly innocent selfportraits - typically taken with a smartphone or webcam and shared via social media - serve many functions. They can be a preened vision of a public self, a bragging moment of accomplishment, a display of humor, or a declaration of irony to the world, almost a performance. The ubiquitous mobile phone with its mirror-image camera technology makes self-portraits easy to take, delete filter, or fix, and even easier to share.

${ }^{9}$ Texto original: Why do we post things that we know could get us in trouble? Are we not thinking it through in the heat of the moment, or do we think no one is paying attention? Are we simply naive, thinking that what we say is only among friends? Or are we the opposite, craving the approval of all those likes or retweets? As we will see, so many times, these messes are entirely of our own making. Your online behavior should be the best reflection of who you are off-line, but so many of us don't live up to that ideal.
} 
A internet é um instrumento muito importante para o desenvolvimento da humanidade e, tal qual o avião, pode ser utilizada tanto para o bem como para o mal. As agressões por meio eletrônico (internet, mensagens via celular ou outros dispositivos eletrônicos) são uma evolução das antigas pichações em muros de colégios, casas ou até nos banheiros das escolas. Eram feitas na calada da noite e causavam grande dor às vítimas, além da impunidade para os seus praticantes. Hoje, os "lobos" mudaram os instrumentos, mas não as práticas. Abrem dolosamente, por exemplo, contas falsas em redes sociais e passam a espalhar mensagens difamatórias ou ameaças contra as vítimas com grande prejuízo para sua honra, saúde emocional e integridade moral.

Se os pais possuem responsabilidade de educar seus filhos e são responsabilizados pelo Código Civil em caso de desídia e omissão de sua parte, não há dúvida que a escola tem deveres jurídicos para impedir, coibir e lidar com situações de bullying e cyberbullying e ela não pode se furtar dessa obrigação.

\section{Responsabilidade civil dos estabelecimentos educacionais por atos de cyberbullying de seus educandos}

O Código Civil (Lei Federal 10.406/02), em seu artigo 186, prevê que aquele que, por ação ou omissão voluntária, negligência ou imprudência, violar direito e causar dano a outrem, ainda que exclusivamente moral, comete ato ilícito. A pergunta inicial é: como enquadrar a responsabilidade nesses casos de Cyberbullying, haja vista que eles são praticados, em grande parte, por incapazes?

O mesmo Código Civil, mais à frente ${ }^{10}$ em seu artigo 932, ao estabelecer situações de verdadeira responsabilidade objetiva, com o objetivo de aumentar a proteção jurídica das vítimas, nos traz respostas para esses casos, ao estabelecer que tanto os pais são também responsáveis pelos atos de seus filhos menores que estiverem sob sua autoridade e em sua companhia (I), como os estabelecimentos educacionais são responsáveis pelos atos de seus educandos.

As escolas, nesse contexto, são, ainda, duplamente responsáveis por força do artigo 14 do Código de Defesa do Consumidor (Lei Federal 8078/90), pois se uma pessoa matricula um

\footnotetext{
${ }^{10}$ Artigo 932. São também responsáveis pela reparação civil: I - os pais, pelos filhos menores que estiverem sob sua autoridade e em sua companhia; II - o tutor e o curador, pelos pupilos e curatelados, que se acharem nas mesmas condições; III - o empregador ou comitente, por seus empregados, serviçais e prepostos, no exercício do trabalho que lhes competir, ou em razão dele; IV - os donos de hotéis, hospedarias, casas ou estabelecimentos onde se albergue por dinheiro, mesmo para fins de educação, pelos seus hóspedes, moradores e educandos; V os que gratuitamente houverem participado nos produtos do crime, até a concorrente quantia.
} 
menor, filho ou filha, num colégio, há uma expectativa que o serviço será prestado com qualidade e eficiência.

E se ocorrem agressões virtuais, justamente por conta de um contrato de prestação de serviços defeituoso, surge, novamente, a responsabilidade de indenizar a vítima.

$\mathrm{Ou}$ seja, podem ocorrer casos concretos, que tanto pais e/ou escolas serão responsabilizados ao mesmo tempo, cada um por haver falhado com seu dever jurídico específico: um por força do artigo 932, I, do CC (pais), e a escola por conta do artigo 932, IV, do CC e o artigo 14 do CDC.

Ou seja, diversas leis brasileiras já previam um dever jurídico por parte das escolas, pelos atos de seus educandos, há diversos anos, e as decisões judiciais em ações de indenizações observaram esses preceitos e, em especial, o artigo 932, IV ${ }^{11}$, do Código Civil, e o artigo 14, I, do CDC.

Nesse sentido, a advertência de Schreiber (2018), de que se respeitando o nexo causal, a escola pode ser responsabilizada civilmente por atos de Cyberbullying de seus educandos:

Um outro caminho que tem sido percorrido na nossa prática judicial é a responsabilização civil da escola. Há diversos dispositivos legais que podem amparar essa opção, que vão desde o artigo $37,6^{\circ}$, da Constituição até o artigo 14 do Código de Defesa do Consumidor, passando, já aí no caso das escolas privadas, pelo artigo 932, IV, do Código Civil. A responsabilização civil da escola constitui via que tem sido seguida em muitos casos de bullying tradicional porque a intimidação sistemática ocorre no ambiente físico da escola, sendo mais fácil, nessas hipóteses, identificar uma falha de fiscalização da instituição de ensino e, portanto, a sua responsabilidade. No Cyberbullying, por outro lado, a discussão afigura-se bem mais complexa porque o dano não ocorre nos limites físicos da escola, mas sim em redes sociais ou grupos de whatsapp criados, muitas vezes, por iniciativa dos alunos e sem qualquer participação efetiva da escola. Os dispositivos legais mencionados retratam hipóteses de responsabilidade civil objetiva, mas não

11 Nesse sentido: TJRS. Número: 70024551392. Órgão Julgador: Décima Câmara Cível. Tipo de Processo: Apelação Cível Comarca de Origem: Comarca de Porto Alegre. Tribunal: Tribunal de Justiça do RS. Seção: CIVEL. Classe CNJ: Apelação. Relator: Jorge Alberto Schreiner Pestana. Acórdão. Ementa: APELAÇÃO CÍVIL. RESPONSABILIDADE CIVIL. RESPONSABILIDADE DO ESTABELECIMENTO DO ENSINO. AGRESSÃO ENTRE MENORES. FALTA DE CUIDADO DA EDUCADORA E DA ESCOLA. AGRAVO RETIDO. DENUNCIAÇÃO DA LIDE. Tratando de responsabilidade fundada no artigo 932, inciso IV, do Código Civil, não procede a denunciação da lide, haja vista a inexistência de direito de regresso do estabelecimento de ensino contra os pais do causador do dano. Ilegitimidade passiva da professora. Sendo a educadora responsável pela vigilância aos menores que se envolveram na agressão, tem legitimidade para responder por danos decorrentes do evento. Tendo a educadora e a escola faltado com o cuidado necessário na guarda dos alunos da turma maternal, cujos antecedentes indicavam a presença de um aluno com histórico de brigas, devem responder pelos danos causados pela agressão (e não agressividade) verificada. Dano moral puro. Ausente sistema de tarifamento, a fixação do montante indenizatório ao dano extrapatrimonial está adstrita ao prudente arbítrio do juiz. Valor da condenação reduzido. Preliminar rejeitada. Apelações providas, em parte. Agravo retido desprovido. Decisão unânime. (Apelação Cível No 70024551392, Décima Câmara Cível, Tribunal de Justiça do RS, Relator: Jorge Alberto Schreiner Pestana, Julgado em 28/05/2009). Data de Julgamento: 28/05/2009. Publicação: Diário da Justiça do dia 23/07/2009. 
dispensam a identificação do nexo de causalidade entre a atividade do educandário e o dano sofrido, devendo-se verificar nos casos concretos se há efetiva presença de nexo causal.

Acontece que, em 2015, a situação da responsabilidade civil para as escolas se agravou mais ainda no campo do Direito. E é o que iremos explicar no próximo tópico.

\section{$O$ advento das primeiras leis federais que regulamentam o combate ao bullying (e o cyberbullying) no brasil no período de 2015-2018}

Como discorremos no item anterior, deveres jurídicos gerais já pesavam contra a escolas, em especial, do Código Civil (CC), Código de Defesa do Consumidor (CDC) e da própria Constituição Federal (CF) de 1988, que demonstravam a responsabilidade objetiva das escolas por atos de seus educandos e, nesse contexto, entendemos que as agressões praticadas entre alunos pela internet ou mensagens de celular se encaixam perfeitamente.

De 2015 a 2018 foram aprovadas três novas leis federais que tratam do assunto e que, em resumo, criaram novos deveres jurídicos específicos para as escolas, reforçando as obrigações anteriores de combate ao bullying, Cyberbullying e toda forma de violência na escola.

São as leis federais 13.185/15, 13.277/16 e 13.663/18.

A Lei Federal 13.185/15 criou os programas de prevenção e combate ao bullying no Brasil e reforçou, no seu artigo $5^{\circ}$, que é dever do estabelecimento de ensino, dos clubes e das agremiações recreativas assegurar medidas de conscientização, prevenção, diagnose e combate à violência e à intimidação sistemática (bullying). Acrescentou essa obrigação jurídica específica às já existentes obrigações jurídicas do CC, CDC e da CF de 1988.

A Lei Federal 13.277/16 cria o dia nacional de combate ao bullying, chamando a atenção para o problema.

E a Lei Federal 13.663/18 ${ }^{12}$ reforça (mais uma vez) as obrigações das escolas, ao inserir na LDB - Lei das Diretrizes e Bases da Educação Nacional (artigo 12) a determinação de que os estabelecimentos de ensino, respeitadas as normas comuns e as do seu sistema de ensino, terão a incumbência de promover medidas de conscientização, de prevenção e de

${ }^{12}$ A Lei 13.663/18 é mais ampla do que a Lei 13.185/15, que trata exclusivamente do bullying e cyberbullying, pois aumenta o dever jurídico das escolas de prevenir e combater toda forma de bullying e determina, ainda, a instauração da promoção de medidas de conscientização, de prevenção e de combate a todos os tipos de violência e a promoção da cultura de paz entre as incumbências dos estabelecimentos de ensino. Conjugando-se as "três leis federais do bullying" com o Código Civil, Código de Defesa do Consumidor e Constituição Federal (artigo $5^{\circ}$, proteção da dignidade da pessoa humana), vê-se que o arcabouço de proteção jurídica das vítimas de bullying e cyberbullying é imenso e traz grandes responsabilidades para as escolas e seus responsáveis legais. 
combate a todos os tipos de violência, especialmente a intimidação sistemática (bullying), no âmbito das escolas (IX), e estabelecerem ações destinadas a promover a cultura de paz nas escolas.

Com o advento dessas três leis federais, que regulamentaram o tratamento do bullying e Cyberbullying no Brasil, ocorrendo casos concretos, em nossa visão, a reprovabilidade é maior do que os atos praticados antes do período de 2015 - 2018.

Em muitos casos, essa situação de omissão dolosa é descoberta no pior momento para a empresa, justo quando vem a público a ocorrência de atos de Cyberbullying, que são repercutidos intensamente nas redes sociais, manchando a reputação do estabelecimento educacional e fragilizando a própria escola, que pode ser processada judicialmente e condenada a pesadas indenizações, e terá poucas chances de apresentar argumentos sólidos em sua defesa, haja vista que lá atrás, em algum momento, algum coordenador pedagógico ou diretor optou por reduzir despesas, desrespeitando os deveres jurídicos das leis federais antibullying e não implantando os programas $^{13}$ antibullying, como são exigidos pela lei brasileira.

\section{Da não implantação efetiva dos programas de prevenção e combate ao bullying criados pela lei $13.185 / 15$ (artigo $4^{\circ}$ )}

Com o advento da Lei federal 13.185/15 foram instituídos programas de prevenção e combate ao bullying nas escolas de todo o Brasil ${ }^{14}$.

Não há dúvida que esses programas, com todos os requisitos apontados no seu artigo $4^{\mathrm{o}}$ (nove incisos ao todo), foram criados para fomentar um ambiente educacional positivo e com uma cultura efetiva de paz nas escolas.

\footnotetext{
${ }^{13}$ Lei Federal 13185/15. Artigo $4^{\circ}$ : Constituem objetivos do Programa referido no caput do art. $1^{\circ}:$ I - prevenir e combater a prática da intimidação sistemática ( bullying ) em toda a sociedade; II - capacitar docentes e equipes pedagógicas para a implementação das ações de discussão, prevenção, orientação e solução do problema; III implementar e disseminar campanhas de educação, conscientização e informação; IV - instituir práticas de conduta e orientação de pais, familiares e responsáveis diante da identificação de vítimas e agressores; V - dar assistência psicológica, social e jurídica às vítimas e aos agressores; VI - integrar os meios de comunicação de massa com as escolas e a sociedade, como forma de identificação e conscientização do problema e forma de preveni-lo e combatê-lo; VII - promover a cidadania, a capacidade empática e o respeito a terceiros, nos marcos de uma cultura de paz e tolerância mútua; VIII - evitar, tanto quanto possível, a punição dos agressores, privilegiando mecanismos e instrumentos alternativos que promovam a efetiva responsabilização e a mudança de comportamento hostil; IX - promover medidas de conscientização, prevenção e combate a todos os tipos de violência, com ênfase nas práticas recorrentes de intimidação sistemática ( bullying ), ou constrangimento físico e psicológico, cometidas por alunos, professores e outros profissionais integrantes de escola e de comunidade escolar.

${ }^{14}$ Embora a Lei Federal 13.185/15 não tenha fixado prazo para a implantação desses programas, entendemos, que fere qualquer parâmetro de razoabilidade, que, em 2019, quatro anos após o advento da referida lei, eles não estejam sendo implantado por todas escolas, públicas e privadas, no país.
} 
Em nosso entendimento, a ocorrência de Cyberbullying em escolas que não implantaram efetivamente esses programas antibullying traz um prejuízo efetivo para alunos, educadores e funcionários administrativos.

Demonstra, ainda, uma maior reprovabilidade por parte do estabelecimento educacional, um caso concreto de desídia e omissão dolosa, que não cumpriu o seu dever jurídico, de lançar mão de todos os instrumentos necessários (e exigidos em lei) para que a cultura de paz seja instalada de forma efetiva.

Muitas escolas, com o objetivo de reduzirem custos, lançam programas mal feitos, ou apenas formalistas, realizam algumas palestras e campanhas isoladas antibullying e Cyberbullying, que não são apenas uma tentativa absurda de enganar as autoridades, como desafiam abertamente as exigências da Lei Federal 13.185/15 em seu artigo $4^{\circ}$.

É óbvio que a reprovabilidade de uma situação de Cyberbullying que ocorre numa escola pública ou privada, após o ano de 2015, onde a escola não implantou efetivamente o programa antibullying com todos os requisitos do artigo $4^{\circ}$ da Lei Federal 13.185/15, é maior ao se comparar a casos de Cyberbullying anteriores a essa lei e onde a escola não tinha, ainda, a obrigação jurídica específica de implantar esses programas.

O prejuízo para os alunos, nas escolas que não respeitam o disposto na Lei Federal $13.185 / 15$, é patente.

Ao se omitirem em implantar programas efetivos e permanentes, não oferecerem formação de qualidade para os educadores e funcionários administrativos sobre como implantar uma cultura de paz, ao não oferecerem assistência psicológica, social e jurídica para vítimas e supostos agressores, a direção da escola, em nosso entendimento, e de forma dolosa, presta um serviço educacional defeituoso (artigo 14, I, do CDC).

E, mais ainda, é patente ser outro agravante o fato de ocorrer ainda uma situação concreta de Cyberbullying que já agrava uma outra falha anterior, que é a não implantação do programa antibullying da lei 13.185/15.

Maior reprovabilidade pela não implantação do programa antibullying da lei federal 13.185/15 gera maior condenação por dano moral. Se não fosse assim, casos de Cyberbullying onde as escolas estavam sob duas situações jurídicas diferentes levariam a condenação por dano moral no mesmo montante, o que seria de profunda injustiça e falta de razoabilidade. 


\section{Reprovabilidade e responsabilidade civil no atos de cyberbullying}

Doutrina e jurisprudência têm se debruçado sobre a responsabilidade do Cyberbullying ${ }^{15}$, praticado, na maioria das vezes, por parte de estudantes, e que já tem sido objeto, inclusive, de diversas condenações judiciais no Brasil.

O problema vem se tornando cada vez mais comum na sociedade e uma série de outras condenações tem surgido em todo o território nacional. Uma série de novos problemas surgiram nos tribunais recentemente com a judicialização da educação.

As discussões judiciais sobre problemas envolvendo a realidade escolar eram reduzidas a trinta anos atrás, e com o avançar da constitucionalização cada vez mais intensa dos direitos, que afetou áreas como a saúde, as políticas públicas, etc, também a Educação passou a ser objeto de mais controvérsias na seara jurídica.

No presente caso, a ocorrência de situações de Cyberbullying envolvendo as escolas, que após o advento da Lei Federal 13.185/15, omitiram dolosamente o dever jurídico de prevenir e combater o Cyberbullying através da implantação dos programas antibullying da referida lei, é o caso de se aplicar a responsabilização civil em valores maiores que os praticados na mesma situação anteriores a 2015, por conta da maior reprovabilidade por parte dessas escolas.

A situação se agrava mais ainda quando nos lembramos do espírito de competição que a escolas particulares disseminam entre os seus alunos, buscando notas altas e aprovações no ENEM - Exame Nacional de Ensino Médio, resultados estes que se revertem em mais matrículas e mais dinheiro para os cofres da escola.

A figura do próximo (ou do Outro) nesse ambiente de extrema competição escolar brasileiro, em especial no ensino privado, e na busca de vagas de alta performance, como aprovações em cursos de medicina nas universidades federais, acaba gerando um ambiente tóxico, propício para o surgimento de ações de Cyberbullying, quando parte dos alunos, equivocadamente, vê o colega como um obstáculo ou um competidor potencial de sua vaga numa boa universidade.

É óbvio que há um dano concreto para toda a comunidade escolar quando a direção da escola ou a sua coordenação pedagógica, no ano de 2019, ou seja, quatro anos após o advento da Lei Federal 13.185/15, dolosamente, se omite, alegando falta de recursos ou até "inefetividade" das normas do artigo $4^{\circ}$ da referida lei, mas que, objetivamente, causa um

15 Trabalhamos com um conceito limitado de Cyberbullying, seguindo parte da doutrina que entende que bullying e cyberbullying são "agressões entre pares". Para os demais casos de agressões pela internet entendemos que o termo adequado são cyberagressões. 
prejuízo efetivo para alunos, educadores, pais e toda a comunidade escolar, pois ela descumpriu um dever jurídico, que deveria ser cumprido com o viés preventivo para situações de bullying e cyberbullying, havendo, então uma lesão ao direito subjetivo da comunidade escolar (dano-evento).

\section{Considerações finais}

Cyberbullying são agressões praticadas entre estudantes pela internet ou por mensagens de celulares (torpedos) e são atos ilícitos civis no Brasil.

Trata-se de um grande problema para as escolas em todo o mundo, e o Brasil possui elevado índice de ocorrências no meio estudantil, o que traz sofrimento para as vítimas e pode gerar um ambiente escolar muito negativo, prejudicando o aprendizado de toda a comunidade.

A vida digital desregrada, a falsa percepção de anonimato, a competitividade das escolas (em especial, as particulares), o individualismo e a falta de investimento em ações preventivas e concretas para coibir o Cyberbullying tem, infelizmente, propiciado o surgimento de um ambiente propício para comportamentos abusivos nas redes sociais entre os alunos de uma escola.

O Direito Educacional, a par de regular as relações da comunidade acadêmica, deve ser aplicado e interpretado com o Código Civil, Estatuto da Criança e do Adolescente, Código de Defesa do Consumidor e Constituição Federal, para regular o assunto.

Infelizmente, com o objetivo de redução de custos, diretores e coordenadores pedagógicos na imensa maioria das escolas não atendem às determinações legais das leis federais que tratam do bullying e Cyberbullying, concorrendo para um ambiente estudantil propenso para o cometimento de atos de Cyberbullying entre os alunos.

Os deveres jurídicos de proteção dos alunos com a responsabilização objetiva dos estabelecimentos de ensino pelos atos de seus educandos, comprovado o nexo causal, previstos no artigo 932, IV, do Código Civil e artigo 14, I (serviço defeituoso) do Código de Defesa do Consumidor, passaram, com o advento das três leis federais do bullying (13.185/15, 13.277/16 e 13.663/18), a possuir uma maior reprovabilidade, e devem ser sancionados, à vista de omissão dolosa por parte das escolas que não implantam os programas antibullying efetivos do artigo $4^{\circ}$ da Lei Federal 13.185/15, com maior intensidade pelo Poder Judiciário, em face das normas jurídicas que regulam a Responsabilidade Civil no Brasil.

A não implantação dos programas antibullying, após o advento da Lei Federal 13.185/15 (artigo $4^{\circ}$ ), demonstra desídia e omissão dolosa por parte da direção das escolas, 
por trazerem prejuízo concreto ao ambiente escolar e desrespeitarem um dever jurídico específico criado para proteger os alunos de agressões de bullying e Cyberbullying.

É totalmente fora da razoabilidade, ferindo o princípio da legalidade e até os direitos fundamentais dos membros da comunidade escolar (educadores, alunos, funcionários administrativos, pais dos alunos etc), que quatro anos após o advento da Lei Federal 13.185/15, grande parte das escolas brasileiras desrespeite ostensivamente essa lei e não tenha implantado programas efetivos antibullying e anticyberbullying em todo o território brasileiro.

\section{REFERÊNCIAS}

AIKEN, Mary. The cyber effect: an expert in Cyberpsychology explains how technology is shaping our children, our behavior, and our values - and what we can do about it. New York: Spiegel \& Grau, 2017.

BAUMAN, Sheri; METER, Diana. Cyberbullying in schools: a review of research in the united states in cyberbullying in schools, workplaces, and romantic relationships. In: GIUMETTI, Gary W; KOWALSKI, Robin M. (Orgs.) Cyberbullying in Schools, Workplaces, and Romantic Relationships. Edição do Kindle. New York: Routledge, 2019.

BAUMAN, Zygmunt. Sobre a educação e a juventude: conversas com Ricardo Mazzeo. Tradução de Carlos Alberto Medeiros. Rio de Janeiro: Zahar, 2013.

BRASIL. Constituição (1988). Constituição da República Federativa do Brasil. Diário Oficial da União, Brasília, 05 out. 1988. Disponível em:

http://www.planalto.gov.br/ccivil_03/constituicao/constituicao.htm. Acesso em: 20 abr. 2019.

BRASIL. Lei Federal n. 8.078, de 11 de setembro de 1990. Dispõe sobre o Código de Defesa do Consumidor. Diário Oficial da União, Brasília, 12 set. 2007. Disponível em: http://www.planalto.gov.br/ccivil_03/Leis/L8078.htm. Acesso em: 14 abr. 2019.

BRASIL. Lei Federal n.10.406, de 10 de janeiro de 2002. Dispõe sobre o Código Civil Brasileiro. Diário Oficial da União, Brasília, 11 jan. 2002. Disponível em: http://www.planalto.gov.br/ccivil_03/leis/2002/110406.htm. Acesso em: 07 maio 2019.

BRASIL. Lei Federal n. 13.185, de 6 de novembro de 2015. Institui o Programa de Combate à Intimidação Sistemática (Bullying). Diário Oficial da União, Brasília, 09 nov. 2015. Disponível em: http://www.planalto.gov.br/ccivil_03/_ato2015-2018/2015/lei/113185.htm. Acesso em: 13 abr. 2019.

BRASIL. Tribunal de Justiça do Distrito Federal e Territórios. Disponível em: https://pesquisajuris.tjdft.jus.br/IndexadorAcordaos-web/sistj. Acesso em: 21 maio 2019.

CABRAL, Stelamaris Rosa; LUCAS, Sônia. Violência nas escolas: desafio para a prática docente? Rio de Janeiro: Gramma, 2010. 
CALHAU, Lélio Braga. Bullying: o que você precisa saber: identificação, prevenção e repressão. 5. ed. Belo Horizonte: D’Plácido, 2019.

COSTA, José Wilson. Cyberbullying In: VALLE, Luiza Elena L. Ribeiro do; MATTOS, Maria José Viana Marinho de (Orgs) Violência e educação: a sociedade criando alternativas. Rio de Janeiro: Wak, 2011.

HAN, Byung-Chul. No enxame: perspectivas do digital. Tradução de Lucas Machado. Petrópolis: Vozes, 2018.

HAN, Byung-Chul. Sociedade do cansaço. Tradução de Enio Paulo Giachini. Petrópolis: Vozes, 2017.

IPSOS. Cyberbullying: a global advisor survey. Disponível na internet em: https://www.ipsos.com/sites/default/files/ct/news/documents/201806/Cyberbullying_june2018.pdf. Acesso em: 08 abr. 2019.

MOSÉ, Viviane. A escola e os desafios contemporâneos. Rio de Janeiro: Civilização Brasileira, 2015.

PENNEY, Jonathon. Internet surveillance, regulation, and chilling effects online: a comparative case study. In: Internet policy review (Forthcoming). Disponível em: https://ssrn.com/abstract=2959611. Acesso em: 10 abr. 2019.

ROCHA, Telma. Cyberbullying: ódio, violência virtual e profissão docente. Brasília: Liber Livro, 2012.

ROUDINESCO, Elizabeth. A análise e o arquivo. Tradução de André Telles. Rio de Janeiro: Jorge Zahar, 2006.

SCHEFF, Sue. Shame nation: the global epidemic on online hate. Naperville: Source books, 2017.

SCHREIBER, Anderson. Cyberbullying: responsabilidade civil e efeitos na família.

Disponível em: http://genjuridico.com.br/2018/10/11/Cyberbullying-responsabilidade-civil-eefeitos-na-familia/. Acesso em: 28 jun. 2019.

PAULINO TOGNETTA, Luciene Regina et al. Bullying e cyberbullying: quando os valores morais nos faltam e a convivência se estremece. Revista Ibero-Americana de Estudos em Educação, v. 12, n. 3, p. 1880-1900, jul. 2017. ISSN 1982-5587. Disponível em: https://periodicos.fclar.unesp.br/iberoamericana/article/view/10036. Acesso em: 14 abr. 2020.

TOGNETTA, Luciene Regina Paulino; VINHA, Telma Pileggi; BOZZA, Thaís Leite. Esses adolescentes de hoje ... convivem como bullying nas escolas? In: TOGNETTA, Luciene Regina Paulino; VINCENTIN, Vanessa Fagionatto (Orgs). Esses adolescentes de hoje ...: o desafio de educar moralmente para que a convivência na escola seja um valor. Americana: Adonis, 2014.

FRICK, Loriane Trombini et al. Estratégias antibullying para o ambiente escolar. Revista Ibero-Americana de Estudos em Educação, v. 14, n. 3, p. 1152-1181, out. 2019. ISSN 
1982-5587. Disponível em:

https://periodicos.fclar.unesp.br/iberoamericana/article/view/12380. Acesso em: 14 abr. 2020.

TRIVINHO, Eugênio. Explosão ciberdromocrática e (trans)política das práticas glocais na civilização tecnológica atual. In: Eugênio Trivinho (Org.). A Explosão do Cibermundo: velocidade, comunicação e (trans)política na civilização tecnológica atual. São Paulo: Annablume, 2017.

WENDT, Guilherme Welter; WEBER, João Luis Almeida. Discutindo agressão e vitimização eletrônica. In: LISBOA, Carolina S. de Macedo; WENDT, Guilherme Welter; PUREZA, Juliana da Rosa (Orgs.). Mitos \& Fatos sobre o Bullying: orientações para pais e profissionais. Novo Hamburgo: Sinopsys, 2014.

\section{Como referenciar este artigo}

REZENDE, Elcio Nacur; CALHAU, Lélio Braga. Cyberbullying, direito educacional e responsabilidade civil: uma análise jurídica e deontológica da realidade brasileira. Revista on line de Política e Gestão Educacional, Araraquara, v. 24, n. 2, p. 494-517, maio/ago. 2020. E-ISSN:1519-9029. DOI: https://doi.org/10.22633/rpge.v24i2.13630

Submetido em: 02/02/2020

Revisões requeridas: $30 / 03 / 2020$

Aprovado em: 10/04/2020

Publicado em: 09/04/2020 